\title{
CAMBIOS EN EL SISTEMA DE CARGOS: A LA LUZ DE LAS COMUNIDADES OTOMÍES EN ACAMBAY
}

\author{
CHANGES IN THE CARGO SYSTEM IN THE LIGHT OF THE OTOMI \\ COMMUNITIES IN ACAMBAY
}

\author{
Leif Korsbaek* y Martín Ronquillo Arvizu*
}

\begin{abstract}
Este trabajo muestra los sistemas de cargos en el municipio de Acambay en el estado de México, dilucidando el concepto de comunidad, que nos permite ver desde una dimensión analítica y explicativa de las características particulares del sistema de cargos, que pone a prueba etnográficamente la idea del típico sistema de cargos, que como una institución en estas comunidades otomíes, adquiere características propias, ya que no se limita solo a aspectos de la jerarquía religiosa, sino que se presentan de forma mezclada con lo que se ha llamado cargos civiles o seculares en las distintas dimensiones de la vida social como es la organización y el control político del municipio.
\end{abstract}

Palabras claves: Sistema de cargos, el típico sistema de cargos, toma de decisiones, control político, participación.

The text contains a description of the cargo systems in the municipium of Acambay in the State of México, with a discussion of the concept of community that allows us to see the particular characteristics of the cargo system, from an analytical and explanatory viewpoint. The point of departure is the idea of the typical cargo system, but the ethnography shows clearly that the cargo system in this part of the State of Mexico acquires its very own characteristics. The cargo system is seen not only as a hierarchical system of religious cargos, it is also seen as an extremely complicated system of religious cargos in articulation with the so called civil or secular cargos, in the various dimensions of the social life, such as the social organization and the social control.

Key words: Typical cargo system, decision making, political control, political participation.

\section{Introducción ${ }^{1}$}

El presente trabajo gira en torno a las comunidades otomíes y sus sistemas de cargos en el municipio de Acambay en el norte del estado de México. Se presentan datos etnográficos y se sintetizan los datos accesibles acerca del sistema de cargos en estas comunidades para analizarlos a la luz de la idea del sistema de cargos en general y en el estado de México en particular.

El núcleo del texto lo constituyen cuatro descripciones etnográficas del sistema de cargos en igual número de comunidades otomíes en el municipio de Acambay. Pathé, San Pedro de los Molcajetes, Pueblo Nuevo y San Francisco Shaxní, sobre la base de esas cuatro etnografías es nuestra intención tratar dos problemas específicos pero estrechamente relacionados del sistema de cargos en las comunidades otomíes en Acambay, uno que podemos llamar interno y otro que se puede llamar externo.

El problema interno tiene que ver con el hecho de que en ocasiones anteriores se ha postulado que la institución conocida como el sistema de cargos juega un papel importante en la creación, la defensa y el mantenimiento de una diferencia étnica y comunitaria ${ }^{2}$.

El problema externo tiene que ver con que, aunque el sistema de cargos es netamente una institución comunitaria pero, como señaló Andrés Medina (1983) en un artículo, no existe en un vacío, está relacionado con el Estado y el mundo exterior. Señalamiento que Nadel observó en el noreste de África "un tipo más profundo de antagonismo, el casi eterno antagonismo entre el Estado desarrollado y la materia cruda de la comunidad" (Nadel, 1935: 303) o, en un ambiente más casero y menos exótico, en un caso en el norte de México se han encontrado "dos racionalidades al interior de la comunidad, es decir, la que ha sido construida con la influencia de los proyectos gubernamentales y que ha latinizado a un grupo de huicholes, y la de los huicholes tradicionales, que se compone de patrones de sobrevivencia y el culto religioso" (Torres, 2000: 283). Finalmente, se pueden agregar otras dos posiciones parecidas: la de Louis Dumont, en

* Escuela Nacional de Antropología e Historia, División de Posgrado de Antropología Social (ENAH-INAH), México. Correo electrónico: leifkorsbaek1941@gmail.com; martinmalagon@hotmail.com 
el caso de la interpretación de las castas en la India (Dumont, 1970), y la posición de Leif Korsbaek en su interpretación del proceso sociocultural en la comunidad matlatzinca de San Francisco Oxtotilpan en el sur del estado de México (Korsbaek, 2009A).

Ahora bien, consideramos pertinente recuperar y discutir la definición conceptual de comunidad, y del municipio, y las interpretaciones hasta ahora vigentes del sistema de cargos en el proceso social. ya que es evidente que la situación y las condiciones de la comunidad indígena han cambiado dramáticamente con la introducción del neoliberalismo como la religión económica ortodoxa en México (y en otras repúblicas en el capitalismo periférico) (el neoliberalismo), hasta tal grado que una institución tranquila y pacífica como es el sistema de cargos se ha convertido en lo que se ha llamado en otro contexto una institución de defensa de la comunidad (Korsbaek, 2009B), y se ha visto en México y en otras partes del mundo que se ha desatado una lucha feroz entre la comunidad indígena y el estado neoliberal.

Al mismo tiempo que el texto se puede ver como una continuación de un anterior texto dedicado al análisis del aspecto político del sistema de cargos en una comunidad indígena en el estado de México, en San Francisco Oxtotilpan (Korsbaek, 2011), se puede considerar como la primera parte de un análisis que se dedicará a entender la participación de la población indígena en el proceso político en otro rincón del estado de México, pues no es tan sencilla como parece y vale la pena mencionar que en el estado de México, que es tan racista como el país entero, si no más, y donde el Grupo de Atlacomulco llevaba sexenios soñando con la presidencia de la República, un sueño que se realizó en 2012 con Enrique Peña Nieto, con el fraude electoral más gigantesco que se ha visto en la historia de México, y que nos ha dejado un México en quiebra, putrefacción moral con el escándalo de Ayotzinapa y la amenaza de una situación de ingobernabilidad.

$\mathrm{Si}$ recuperamos algunas situaciones que nos ilustran que lo secular y lo religioso como parte de un mismo proceso, al presenciar a un indígena mazahua como presidente en el municipio de Donato Guerra, y en otra ocasión vimos a un indígena otomí como presidente en el municipio de Chapa de Mota y, como señala la descripción del sistema de cargos en San Francisco Shaxnì, una situación nada sencilla en el municipio de Acambay, ya que un sujeto puede ocupar dos cargos en ambas estructuras.

\section{El concepto de comunidad y el municipio}

El concepto de "comunidad" es uno de los conceptos clave para el entendimiento de las relaciones internas, pero surge una sospecha de que no ha sido definido con precisión más allá del sentido común, y una revisión de la bibliografía relevante tiende a confirmar esta sospecha. Según la Ley de Hobsbawm, todos sabemos qué es una comunidad, pero hay cierta generalidad en el uso del concepto y en la antropología "existe un cierto consenso en considerar a la sociedad como: (1) un grupo de personas (2) que interactúan entre sí (3) y se hallan organizados e integrados en una totalidad. Estos tres elementos constituyen otras tantas partes indispensables de cualquier definición científica del término sociedad" (Rossi \& O'Higgins (1981: 39), haciendo referencia a "Alfred Kroeber, Ralph Linton, Clyde Kluckhohn, A. R. RadcliffeBrown, Robert Redfield y Julian Steward", que "han propuesto distintas definiciones del término sociedad"), tal vez porque el problema de definir a la comunidad por lo regular ha sido relegado a lo social, que es supuestamente mucho más sencillo que lo cultural, según Linton, por ejemplo, quien señala que "la sociedad es simplemente un grupo organizado de individuos; la cultura, por lo contrario, es un grupo organizado de ideas, hábitos y respuestas emocionales condicionadas, compartidas por los miembros de una sociedad" (1956: 205).

La comunidad es el espacio de la seguridad y de la confianza, donde las cosas están en su lugar, no es un costal de papas, como decía en algún momento Carlos Marx acerca de los campesinos franceses. La comunidad es caracterizada por su estructura, tanto horizontal como vertical, que asegura que los miembros de la comunidad se puedan relacionar ordenadamente con su colectividad y con los demás miembros, y también con las gentes que no pertenecen a la comunidad, con los forasteros. La comunidad también tiene historia: su desarrollo a lo largo del tiempo tampoco carece de orden y sentido, pero la historia de la comunidad le asegura su coherencia.

Para fines del presente trabajo, una comunidad, como concepto, tiene que poseer seis características: es un proyecto llevado a cabo por una colectividad, frecuentemente pero no siempre dentro de un marco territorial, que tiene coherencia horizontal, coherencia vertical e historia.

Este proyecto se lleva a cabo por un grupo de gentes, lo que significa, en primer lugar, que no es 
un proceso natural (el ser humano es, como unidad biológica, una unidad casi universalmente aceptada), sino social y cultural y, en segundo lugar, que no es un proceso individual, sino colectivo (lo que complica el uso de la analogía de organismo y deja a los participantes en el proceso cierta libertad que no tiene las partes de mi cuerpo en los movimientos del mismo).

Típicamente el proceso que es la comunidad se lleva a cabo dentro de un marco territorial, sin embargo, no siempre es el caso, y no siempre la territorialidad tiene el mismo significado. Por un lado podemos construir una especie de geografía espiritual, donde lo que cuenta no son los elementos físicos del ambiente, sino el sentido y el significado que tienen estos, y por otro lado podemos considerar los casos de los gitanos y los judíos que aparentemente no cuentan con un marco territorial, pero sí lo tienen exactamente en el sentido de una geografía espiritual.

Con coherencia horizontal se quiere decir que tiene "estructura", pues sus diferentes miembros están de alguna manera mutuamente ordenados en un momento dado. El concepto de estructura surge muy temprano en inglés como descripción del "esqueleto" de un edificio (como si fueran precursores de Durkheim y sus cosas), pero sin pretensiones de ser una panacea metodológica y teórica, y en el siglo XVI se utiliza para referir a cualquier parte en su relación a una totalidad, especialmente en la anatomía (Leach, 1967: 482). La comunidad tiene una estructura que articula a los diferentes elementos, empíricos y menos empíricos, en una totalidad. Es sabido que del concepto de estructura existen variadas definiciones y concepciones (aparte de uno que otro autor que opina que el concepto no sirve para nada, como por ejemplo Kroeber, 1948: 325). Mientras que Radcliffe-Brown, siguiendo los cánones del empirismo británico, define la estructura social como "el conjunto de relaciones eventualmente existentes, en un momento dado, que relaciona un número de seres humanos", subrayando que pertenece a "la realidad concreta" (Radcliffe-Brown, 1940: 192), y se puede observar directamente en el campo, sin necesidad de acudir a abstracciones más allá de la observación misma, y una orientación racionalista cuyos representantes más articulados son Lévi-Strauss y Edmund Leach (la clásica definición empirista se encuentra en Radcliffe-Brown, 1940, mientras que las definiciones estructuralistas se encuentran en Lévi-Strauss, 1953 y Leach, 1965).
Con coherencia vertical se quiere decir que la comunidad abarca diferentes niveles que están articulados. El primer nivel es el nivel social, en el sentido más amplio, y el segundo nivel es el nivel ritual, donde los roles no son los roles sociales de la vida cotidiana, sino roles rituales que pertenecen al espacio sagrado, o secular, y donde los roles se pueden caracterizar como roles del sistema de cargos. En estrecha relación con discusiones de la comunidad (y, ocasionalmente, con esfuerzos por definir la misma) abundan declaraciones como: "la comunidad es el grupo dentro del cual es posible disfrutar la buena vida, como los nyakyusa la perciben. La buena vida es ukwangala, es decir, el goce de la compañía de los iguales de uno" (Wilson, 1967: 223).

Y finalmente existe el nivel de comunitas, que es el último nivel de legitimación y autorreferencia y donde no existen roles, pues "es como si existiera aquí dos modelos mayores de las relaciones humanas, yuxtapuestos y alternantes. El primero es de la sociedad como un sistema estructurado, diferenciado y frecuentemente jerarquizado de posiciones político-legal-económicas con muchos tipos de evaluación, separando a los hombres en términos de más o menos. El segundo, que emerge distinguible en el periodo liminal, es de la sociedad como un comitatus no estructurado o rudimentariamente estructurado, comunidad, o aún comunión de miembros de individuos iguales que juntos se someten a la autoridad general de los ancianos especialistas rituales", pero "la distinción entre la estructura y la comunitas no es sencillamente la familiar distinción entre lo secular y lo sagrado ni, por ejemplo, entre la política y la religión": "eso no es sencillamente, como ha propuesto sabiamente Fortes, una cuestión de proporcionarle un sello general de legitimidad a las posiciones estructurales de una sociedad. La cuestión es más bien la de conferirle reconocimiento a una relación humana esencial y genérica, sin la cual no podría haber sociedad alguna" (Turner, 1969: 83, haciendo referencia a Fortes, 1962: 86). En los trabajos de Turner no hemos visto ninguna referencia a Toennies, pero siento que su concepto de comunitas es muy similar al concepto de Toennies de Kurwille, y puede muy bien venir de allá originalmente, con lo que Turner (y Fortes) se acerca al planteamiento de Simmel: “¿cómo es posible la sociedad?" (1910). Lo que caracteriza a una comunidad es que tiene historia, con lo que 
se presenta la complicación de definir ¿qué es la historia? Las definiciones tienen que ver con el tiempo, y existe una variada gama de opiniones acerca de qué tiempo: el pasado, el presente o el futuro. Ahora bien pensamos que el tiempo que tiene mayor importancia en la historia es el futuro, sin de ninguna manera querer minimizar la importancia del pasado y del presente. El criterio de la existencia de una comunidad es la existencia de un proyecto social. Las gentes que comparten una comunidad comparten también, de manera comprometida, un proyecto social, que puede asumir las formas más variadas.

Para asegurar la existencia de la comunidad se requiere una institución que la aglutine horizontal y verticalmente, encapsulando su historicidad como proyecto, y esta institución es, en determinados casos, la institución conocida como el sistema, sistema de cargos que si los pensamos desde Parsons que se reconoce como un teórico incurable, nunca perdió de vista la importancia y relevancia de tomar en cuenta datos empíricos, o bien los productos de la acción humana, a los que llamó acción social. Por ello la relevancia de disertar acerca de aspectos de necesidades, instituciones y socialización, que ello lo llevó a explicar la forma en que el sujeto internaliza normas socioculturales, valores, pautas morales.

Si pensamos un sistema de cargos, como un subsistema de la acción, ya que el peso, la influencia y el compromiso que tienen los sujetos con los compromisos configuran todo un sistema de interrelaciones que se establecen en el mantenimiento de pautas de acción dentro de un sistema sociocultural. "Los sistemas de acción se estructuran en torno a tres focos integrativos: el actor individual, el sistema interactivo y un sistema de pautas culturales" (Parsons, 1982: 35).

En los sistemas sociales simples, estos factores son adscritos; "esto es así en relación con las sociedades primitivas y también respecto de los sistemas socializadores dentro de los cuales, en la sociedad más diferenciada, está colocado el niño durante su etapa de socialización" (Parsons, 1986: 58).

En la medida en que se internalizan las necesidades y motivaciones, como pautas constituyen una conducta uniforme que va conformando parte de la estructura del sistema cultural de orientación: sistema de ideas o creencias cognitivas, sistema de pautas ajustadas o símbolos expresivos, sistemas de pautas integrativas o criterios de orientación de valor; todos estos tienen como finalidad y propósito orientar la acción de manera concreta en relaciones específicas.

Así, el sistema de cargos permite la interacción social a partir de valores comunes, reglas comunes, normas jurídicas de orientación colectiva que forman un sistema de relaciones que ponen en juego un proceso de aprendizaje cultural de la vida; es la forma de internalizar las pautas de conducta, los valores comunes que se expresan en actitudes apropiadas, en recompensas, en sanciones y castigos que pueden ser aceptados, compartidos o rechazados, pero forman parte integral del sistema de pautas de orientación. En este contexto es relevante mencionar que el sistema de cargos es solamente una entre varias "instituciones equivalentes", es la solución histórica que se ha venido desarrollando en las comunidades campesinas en Mesoamérica $\mathrm{y}$ en los Andes, en otras regiones se han venido desarrollando otras instituciones integradoras. Y puede ser relevante mencionar el proceso de mea culpa, por el que está pasando Leif Korsbaek, por haber introducido y promovido la "cargología", el estudio sistemático del sistema de cargos, reificando esta institución, en vez de dirigir la atención al problema real, a la comunidad.

La importancia de las pautas motivacionales culturales para el funcionamiento de una sociedad radica en su eficacia y efectividad, pensar el sistema de cargos como una institución que comparten los miembros de una colectividad por lo general se liga a aspectos religiosos o morales que se mezclan y se tornan complejos en el sistema sociocultural: "Las creencias religiosas, pues son aquellas que se ocupan de los problemas morales de la acción humana, de los aspectos de la situación humana, y del lugar que ocupa el hombre y la sociedad en el cosmos, que mayor relevancia tienen para sus actitudes morales, así como de las pautas de orientación de valor" (Parsons, 1982: 344).

Finalmente, podríamos decir que en los sistemas de cargos se configura un criterio de lealtad hacia una colectividad en la medida que estas se han institucionalizado (varias imágenes concretas), que corresponden a los intereses colectivos, implica que los sujetos tomen en cuenta ciertas gratificaciones de carácter individual, ya que la orientación tiene que ver con los cánones de validez socialmente construidos, a pesar de apelar al sistema cultural como la categoría que le explique el porqué de las conductas y las acciones, no deja de lado su dimensión normativista de la sociedad. 
Faltaría, sin embargo, tratar un problema: el presente texto discute el funcionamiento del sistema de cargos en el marco del municipio. Sin embargo, ya que el sistema de cargos es netamente una institución comunitaria, se nos presenta el problema de la articulación de la comunidad con el municipio y el papel del sistema de cargos en esta articulación.

El municipio pertenece al mundo moderno, pues fue introducido como parte de la conquista española, así como lo señala Francois Chevalier en su estudio de Los municipios indígenas en la Nueva España, 1520-1620: donde "Una de las características de la colonización española es, sin lugar a dudas, haber intentado exportar, sin modificación alguna, las instituciones religiosas, políticas y sociales vigentes en la península a los países recientemente descubiertos" (Chevalier, 1944: 352), y una de esas instituciones fue exactamente la idea del municipio.

Normalmente, no coincide la comunidad con el municipio, hay casos, pero son raros, uno de los casos mejor conocidos lo encontramos en el estudio de Pinola, pero es mucho más común que el municipio contiene muchas comunidades. De los clásicos estudios de cargología en Chiapas se pueden mencionar los de San Juan Chamula, de Zinacantán, donde el municipio de Zinacantán abarca 17 comunidades y San Juan Chamula más de 100 (Pozas, 1977; Cancian, 1976).

En la legislación moderna, "en la Constitución de 1857 hay referencias al municipio (primera vez que aparece el término) en el art. 31, fracción II, donde se establece como obligación de todo mexicano "contribuir a todos los gastos públicos, así de la Federación como del Estado y Municipio en que resida" (Lira, 1987: 51).

Ya se mencionó que el talón de Aquiles de la cargología (el estudio antropológico del sistema de cargos) es el estudio del aspecto político, y son pocos los estudios que de manera sistemática trata el aspecto político del sistema de cargos en el marco del municipio. Aparte del estudio clásico de Gonzalo Aguirre Beltrán, un curioso caso es el estudio comparativo que hizo Evon Z. Vogt de Zinacantán y San Juan Chamula, en el que señala (con marcada alusión a la cuestión religiosa) que "Parece que existe una interrelación decisiva entre los dioses y la estructura de lo político en Zinacantán y en Chamula, como lo descubrió recientemente el obispo católico de San Cristóbal de las Casas, cuando en 1968 decidió promover la construcción de una capilla en una de las aldeas alejadas en Chamula,
La Candelaria. La oligarquía chamula movilizó varios cientos de hombres armados para parar la construcción. Además, el cura católico residente recibió advertencias nada ambiguas de los líderes chamulas, que se quedara en la iglesia de San Juan y ni siquiera visitara las aldeas. Cuando más tarde intentó intervenir contra la ejecución de algunas de las ceremonias tradicionales dentro de la iglesia, fue expulsado de Chamula y ahora solamente regresa para celebrar misa y bautizos. El obispo descubrió que Chamula no es como Zinacantán, y más tarde me contó en una entrevista que la experiencia entera lo intrigó. En pocas palabras, parece que tanto la política como los dioses se encuentran firmemente controlados por la oligarquía de Chamula" (Vogt, 1973: 108).

Se mencionó un caso liminal, el Pinola de Esther Hermitte, pero sería relevante mencionar otro caso liminal: se señaló en una ponencia hace unos años que la presión neoliberal ha convertido una institución tan romántica como el sistema de cargos en una institución de defensa de la comunidad, en el caso de México, recientemente en algunas nuevas instituciones en varias partes de la República (Korsbaek, 2014), en el Perú en la institución conocida como la ronda campesina (Korsbaek, 2012). La ronda campesina es más que notable, pues es la única institución comunitaria que ha llegado a nivel nacional, hasta tal grado que en las recientes elecciones presidenciales, el 10 de abril del año en curso, un líder de la ronda campesina, Gregorio Santos, "Goyo", participó en las elecciones como candidato, y por cierto desde la cárcel, donde está purgando una condena de 18 meses.

\section{El sistema de cargos}

La institución conocida como el "sistema de cargos" ha sido estudiada desde 1937, cuando fue "descubierto" por Sol Tax (1937), desde todos los ángulos imaginables y por medio de un gran número de métodos. El punto de partida es que "uno de los rasgos fundamentales de las comunidades tradicionales de indios campesinos de Mesoamérica es la jerarquía cívico-religiosa que combina la mayor parte de los cargos civiles y ceremoniales de la organización de la ciudad en una única escala de cargos anuales" (Carrasco, 1979: 323) y, en un conocido caso de Chiapas, que "es como si los zinacantecos hubieran construido un modelo para la conducta ritual y para la conceptualización del 
mundo natural, que funcionara como una especie de computadora que imprimiera las reglas de conducta adecuadas para cada nivel organizativo de la sociedad y su aplicación para los fenómenos en los diferentes dominios de la cultura" (Vogt, 1965: 129).

Como resultado de numerosas investigaciones antropológicas se ha formulado el típico sistema de cargos: Este típico sistema de cargos

consiste en un número de oficios que están claramente definidos como tales y que se turnan entre los miembros de la comunidad quienes asumen un oficio por un período corto de tiempo después de lo cual se retiran a su vida normal por un largo período de tiempo. Los oficios están ordenados jerárquicamente y el sistema de cargos comprende a todos $-\mathrm{O}$ a casi todos- los miembros de la comunidad. Los cargueros no reciben pago alguno durante su período de servicio, por el contrario, muy a menudo el cargo significa un costo considerable en tiempo de trabajo perdido y en gastos en dinero en efectivo, pero como compensación el cargo confiere al responsable un gran prestigio en la comunidad. El sistema de cargos comprende dos jerarquías separadas, una política y una religiosa, pero las dos jerarquías están íntimamente relacionadas, y después de haber asumido los cargos más importantes del sistema un miembro de la comunidad es considerado como pasado o principal (Korsbaek, comp., 1996:82).

A un nivel analítico y explicativo esta oleada de investigaciones nos dejó lo que ha sido llamado el paradigma de cargos. Taquigráficamente podemos caracterizar este paradigma de cargos, que por razones tan arraigadas como cuestionables ha sido dividido en tres aspectos: un aspecto económico, uno político y uno religioso o ideológico; así, se postula que esta institución tiene la función económica de nivelar la riqueza (y la pobreza) en la comunidad indígena, políticamente de asegurar la democracia en la misma comunidad, mientras que podemos dividir su aspecto religioso e ideológico en cuatro postulados: define a la comunidad, es decir, produce la identidad étnica y comunitaria, define las fronteras de la comunidad, define los canales legítimos de comunicación entre la comunidad y las autoridades eclesiásticas y políticas del sistema nacional, y finalmente es una institución conservadora que se opone a cualquier cambio en la comunidad (el paradigma de cargos se encuentra en Korsbaek, comp., 1996: 271-292).

En términos generales se ha perdido la confianza en la mayor parte de los postulados del "paradigma de cargos", que se relaciona con una tendencia romántica en los antropólogos: es ya reconocido que el sistema de cargos no nivela nada y que no tiene nada que ver con la democracia, legitima muchas prácticas de desigualdad, pues coexiste perfectamente con el cacique y, en lo que se refiere a su aspecto religioso, se sabe que no es necesariamente una institución conservadora que se opone a cualquier cambio en la comunidad. Pero sí es reconocido que define a la comunidad, es decir, produce la identidad étnica y comunitaria, define las fronteras de la comunidad, y hasta cierto grado define los canales legítimos de comunicación entre la comunidad, las autoridades eclesiásticas y políticas del sistema nacional.

Es importante recordar que, en 1982 declaró Daniele Dehouve en una reunión informal (con ocasión del Congreso Internacional de Latin American Studies Association) en la Ciudad de México que "el sistema de cargos no existe". Para formular una respuesta, que sea positiva, negativa o neutra, a esta opinión, evidentemente se requiere la formulación de una definición del sistema de cargos, más allá de la definición tradicional. Esta nos lleva a otras cuatro provocaciones, que plantean la misma necesidad: la de definir seriamente lo que es el sistema de cargos. En primer lugar, la observación de Reyes Luciano Álvarez Fabela (2007), de que "un mayordomo no hace sistema", que se tiene que ver en conjunto con las observaciones críticas de Hilario Topete Lara (2007) y de Saúl Millán (2003), cada uno en sus respectivas y muy respetables tesis doctorales.

Desde aproximadamente 1995, los estudios en el estado de México nos han mostrado que el "típico sistema de cargos" no es típico en las comunidades indígenas en el estado de México, siendo las principales diferencias la participación, la articulación de lo político y lo religioso, la responsabilidad de los gastos relacionados con la ocupación de un cargo y la jerarquización de los cargos (la distancia del sistema de cargos en las comunidades indígenas en el estado de México y el típico sistema de cargos ha sido discutida en Korsbaek, 2000, 2002, 2007). 
La cargología estaba ya muy avanzada en otras partes de Mesoamérica cuando se inició el estudio antropológico del sistema de cargos en las comunidades indígenas en el estado de México: ya se había formulado una idea bastante precisa acerca del típico sistema de cargos, es decir, la forma y la estructura general y repetida de esta institución en diversas partes de Mesoamérica, y su funcionamiento, así como se expresa en el paradigma del sistema de cargos.

Muy en especial se compara el perfil de los sistemas de cargos en Acambay con las desviaciones del típico sistema de cargos en el estado de México del llamado típico sistema de cargos en el sureste: la participación plena, la articulación de las jerarquías religiosa y civil y la distribución de los gastos relacionados con la ocupación de un cargo. Otro aspecto que recibe atención es el papel del sistema de cargos de las comunidades indígenas con el Estado nacional, a sus diversos niveles en las relaciones y administración secular.

\section{Los cargos en Acambay: aproximaciones etnográficas}

El municipio de Acambay se encuentra en el estado de México y es identificado por su cercanía con el municipio de Atlacomulco. Dentro de la región norte que se compone de 10 municipios, Acambay colinda al norte con el municipio de Aculco; al sur con los municipios de Temascalsingo, Atlacomulco y Timilpan, también marca el límite con el estado de Querétaro. Políticamente cuenta con 97 localidades y de estas aproximadamente 25 son caracterizadas como indígenas otomí, una población para el 2010, según el INEGI, de 56.849 habitantes.

Es posible señalar que lo relevante de las comunidades indígenas en el municipio de Acambay es que presentan un sistema de cargos muy latente y enredado, ya que sus particularidades se pueden reducir al "típico sistema de cargos"; donde coexiste con políticas y proyectos que tienen la intención de "mejorar las condiciones de los municipios", pero formulan dichas políticas y proyectos por los "no indígenas"; y encontramos que existen municipios controlados y dominados en las cabeceras por los "no indígenas" y la población indígena en su mayoría está en las comunidades. Por lo anterior podemos decir que en Oaxaca, Chiapas, Guerrero, hay municipios indígenas y que Acambay es un municipio con comunidades indígenas.
Por lo anterior consideramos que el debate de la temática también se puede presentar haciendo un recuento, o bien una reconstrucción histórica sin ningún referente etnográfico, como lo muestra la siguiente cita:

Respecto al estado de México, desde 1995 Leif Korsbaek ha estudiado las comunidades indígenas en dicha entidad. El proyecto comenzó en la facultad de antropología de la Universidad Autónoma del estado de México, en Toluca y concluyó en la Escuela Nacional de Antropología e Historia. Implicó un profundo análisis etnohistórico en algunas de las 328 comunidades del estado de México, en que consideró los siguientes objetivos: conocer cómo y cuáles eran las características del sistema de cargos, comparar con los estudios del sureste mexicano dónde se identifica un 'típico sistema de cargos' y comprender el paradigma con que este sistema ha sido descrito, más desde una idea romántica de los antropólogos que desde una perspectiva del ambiente indígena en donde prevalece (Reina; 2015:107).

Sin embargo es factible aclarar que el proyecto aun continúa y sí es una idea romántica, ya que está sustentado en trabajo de campo, y no solo es una aproximación con referentes históricos; por ello en seguida presentamos aproximaciones etnográficas del sistema de cargos en algunas de las cuatro comunidades otomíes, donde podemos distinguir los rasgos compartidos poniendo énfasis en la forma en que se expresan y presentan, la forma en que se entrelazan los cargos seculares o civiles y los cargos religiosos, por ejemplo: en la vida social la ocupación del cargo tiene relación con los partidos políticos, estos se reducen por momentos a un estricto cuerpo de elites como, fiscales, los mensajeros o padrinos a cada comunidad, jefes de partido, delegados al municipio, diputados, líderes religiosos.

Un número de oficios que están claramente definidos como tales y que se rotan entre los miembros de la comunidad, quienes asumen un oficio por un periodo corto, después de ello se retiran a su vida normal por un largo tiempo. Los cargueros no reciben pago alguno durante su periodo de servicio, por el contrario, muy a menudo el cargo significa un costo considerable en tiempo de trabajo 
perdido y en gastos en dinero en efectivo, pero como compensación el cargo confiere un gran prestigio en la comunidad.

Hay un detalle que bien podría ser lo más importante en este artículo y merece una investigación más profunda en adelante. Es claro que el sistema de cargos es netamente una institución comunitaria, pero como señala Andrés Medina (1983), el sistema de cargos no se queda encerrado en la comunidad, tiende sus tentáculos hacia fuera, más específicamente hacia las instituciones del estado y el mundo moderno, y como ha señalado Leif Korsbaek (2009A: 225), "en la comunidad surgen nuevas instituciones".

Cuando iniciamos el trabajo de campo en Acambay en 2004 existía ya en la cabecera del municipio un cuerpo de cuatro "mensajeros" que mantenía la comunicación entre la cabecera y las comunidades del municipio, cubriendo los cuatro caminos que se desprenden del mapa.

Posteriormente, el presidente municipal Salvador Navarrete Cruz (2008-2011) convirtió este cuerpo de mensajeros en una red de "padrinos", uno en cada comunidad, que al mismo tiempo aseguraron la comunicación entre las comunidades y la cabecera, y ya que todos eran del PRI y allegados al gobierno municipal, contribuyeron no solamente a la comunicación entre su comunidad y la cabecera, sino también al control de las comunidades por parte de la cabecera. Parece que el presidente municipal Irineo Ruiz González (20011-2015), originario de San Francisco Shaxní, abolió la red de padrinos y ha vuelto al anterior cuerpo de mensajeros y delegados como la forma de comunicar políticamente a las comunidades.

\section{Pathé. Las dos dimensiones de los cargos $^{3}$}

La forma en que se organiza políticamente la comunidad de Pathé abarca dos dimensiones que pasa por cuestiones civiles y religiosas; aunque se muestran bien demarcados los ámbitos, se hallan imbricados. Esta estrecha vinculación tiene sustento en la participación de los miembros de la comunidad para la elección de los representantes civiles y religiosos, donde la toma de decisiones pasa por una Asamblea General, la que está integrada por los jefes de familia. A esta asamblea en su mayoría asisten los varones, pero cuando no es posible, son las mujeres quienes la conforman. Esta asamblea cobra validez cuando la mayoría de los jefes de familia asisten; si no es el caso, se le pospone para una fecha próxima (según sea lo urgente de las decisiones que haya que tomar); cuando la decisión apremia se toma con los presentes.

La toma de decisiones es por medio de votación directa; esta es visual (cada asistente levanta la mano). Cuando hay mayoría, la decisión se toma en acuerdo, que lo hace obligatorio para cada uno de los miembros de la comunidad. En Pathé el responder colectivamente se expresa en la Asamblea General, que funciona como la institución que regula la organización de la vida civil y religiosa de la comunidad. Es por intermedio de ella como la comunidad elige no a un gobernante sino a un representante y sus auxiliares, quienes no pueden tomar una decisión de importancia sin consultarla. La Asamblea elige a un delegado municipal, un subdelegado, un presidente de bienes comunales y un tesorero (con sus respectivos suplentes). ${ }^{4}$ Cada uno de los miembros de este órgano de representación tiene tareas bien delimitadas. El delegado es la persona de que se sirve la comunidad para vincularse con el municipio $\mathrm{El}$ rol al interior de la comunidad es el de coordinar los trabajos y recursos que se requieran para afrontar alguna necesidad, ya sea alguna reparación o construcción que implique consecuencias colectivas.

El delegado es el que lleva a cabo las gestiones ante la autoridad municipal para que a la comunidad se le dote de servicios públicos (red de agua potable, instalación de luz eléctrica, sea domiciliaria o de alumbrado público, recolección de basura, etc.). También tiene que asistir a las reuniones a que los convoca las autoridades municipales, casi siempre son para informarles acerca de los proyectos estatales o federales, de los recursos disponibles (económicos o materiales) para la realización de alguna obra (arreglo o trazado de alguna de las calles, ampliación de la red eléctrica o de agua potable).

El subdelegado lo asiste al acompañarlo o llevando a cabo los trámites necesarios ante las instancias pertinentes. El tesorero resguarda los recursos económicos (ya sean de cooperación de los miembros de la comunidad o de aquellos que provienen del municipio) y lleva la contabilidad de los ingresos y egresos que se realizan durante la gestión. Los asuntos que conciernen a linderos, recursos naturales (bosques y ciénega) y cualquier controversia respecto de terrenos comunales los gestiona el presidente de bienes comunales, aunque 
no quiere decir que sea un cargo independiente del delegado, antes bien, contribuye y participa muy estrechamente con su gestión.

En Pathé, la presión social que sienten los que son propuestos y elegidos para una nueva gestión pasa por los mismos jefes de familia que conforman la Asamblea General, y que los obliga, de cierta formar, aceptar el cargo.$^{5}$ Los cargos arriba mencionados son de carácter honorario, no hay remuneración monetaria alguna. Son funciones que hallan sus raíces en la imperiosa necesidad de responder en conjunto como un todo. Estos cargos, además de simbolizar el ser social de la comunidad, representan la fiabilidad que hay entre cada uno de los miembros de Pathé, el colectivo traduce en la confianza que deposita en las personas encargadas de llevar los asuntos importantes del pueblo. El proceder de las personas que han sido elegidas para los cargos repercute en la opinión pública favorable o negativa que se tenga de ellas; si su conducta es honesta y seria para ejercer el cargo, lograrán, aunque esa no sea su intención, cierto grado de respetabilidad (prestigio), que tiene su inmediata consecuencia en la importancia que adquieren sus comentarios y propuestas dentro de las Asambleas en las que se habla de las últimas gestiones anteriores y se expresan opiniones (desprestigio) acerca de los malos manejos (desvíos que tuvieron tanto de recursos económicos como materiales, y que utilizaron para beneficio propio).

Otra dimensión de la organización política de la comunidad es también la que concierne al ámbito religioso y, sin duda, es la que reafirma la participación colectiva. Un primer nivel lo constituye la institución que resguarda los instrumentos de culto y los recursos monetarios, la gente que asiste al sacerdote en las celebraciones litúrgicas y preside, cada año, la organización de los cargueros.

Los fiscales simbolizan la obligatoriedad asumida por la comunidad ante la reciente elevación a categoría de parroquia del templo de Pathé, ello ha incrementado el tiempo y trabajo de los fiscales sometiéndose a opinión pública entre los miembros de la comunidad, ya que son quienes reciben el pago por asistencia en los oficios y celebraciones. De esta suerte, al sentido simbólico de la obligatoriedad asumida que representaban los fiscales se le ha sumado el elemento económico, y la relación entre la iglesia y la religiosidad de la comunidad ya no se sustenta únicamente en la representatividad comunitaria, sino también en una de carácter personal, en donde la relación del ministro con los fiscales ha adquirido un matiz laboral; en donde la subordinación que significa la jerarquía de ser representante de la Iglesia.

Un segundo nivel jerárquico, pero de mayor importancia, que constituye la organización social de Pathé es la institución de los cargueros. En esta estructura paralela pueden coincidir (de hecho coinciden) personas que integran las otras estructuras, sean de carácter civil (delegado, subdelegado, etc.) o religiosa (fiscales). La comunidad está dividida en cuatro sectores, conformados por aproximadamente sesenta y cinco familias. A cada parte le corresponde durante un año hacerse cargo de las fiestas del Santo Patrón. Al asumir la responsabilidad un sector, eligen a cuatro Cargueros Mayores, que serán los que organicen, acopien y administren los recursos económicos a lo largo del año para las festividades. Los Cargueros Mayores distribuyen el orden jerárquico al interior de la estructura, el que obedece a la importancia de las decisiones que tiene que tomar cada uno: Carguero Mayor $1^{\circ}$, Carguero Mayor $2^{\circ}$, Carguero Mayor $3^{\circ}$ y Carguero Mayor $4^{\circ}$. El Carguero Mayor $1^{\circ}$ tiene la mayor responsabilidad en la organización de los eventos y en caso de ausencia, el siguiente, y así sucesivamente.

A su vez, los mayores eligen a cuatro ayudantes, Cargueros Menores, dos de ellos tienen la función de Pasios. Los cuatro Cargueros Menores auxilian en la recaudación de los recursos y la organización de las festividades; no hay duda de que el trabajo de mayor esfuerzo físico es el del Carguero Mayor ${ }^{\circ}$ y Las Pasios. La estructura jerarquizada refleja la división del trabajo dentro de la unidad familiar. El Carguero Mayor lo conforma una familia de esposo y esposa, en caso de ausencia lo suple un hijo o hija, según sea el caso. El varón se hace cargo de la organización de los hombres para los trabajos que requieran un esfuerzo físico, previo o durante las festividades; la mujer realiza la función de Carguera Mayor, organiza a las mujeres para el arreglo y limpieza de la iglesia, y portan el incensario con el copal a todas las festividades donde la requieran, sea dentro o fuera de la comunidad. Dentro de esta jerarquía, la Mayor y la Pasio son las que llevan a cabo el mayor esfuerzo físico que exige el ciclo de ritualidades en que está insertada la comunidad de Pathé. Estas dos dimensiones de los cargos nos muestran que la dimensión civil o política se encuentra entrelazada con la dimensión 
religiosa y facilita el control, la cohesión y muestra la diferencia de la comunidad.

\section{San Pedro de los Molcajetes, sus cargos y su fiesta ${ }^{6}$}

Como carta de presentación, esta comunidad se distingue por su actividad económica, ya que una buena parte de la población se dedica a la elaboración de molcajetes. Al llegar al lugar, lo primero que se escucha es el sonido de un cincel y de un martillo golpeando una piedra, para dar forma a un molcajete.

En términos de cargos, en San Pedro tienen autoridades cívico-políticas de San Pedro que mantienen una relación directa con el municipio vía un delegado y subdelegado, elegidos en asamblea. El primero se encarga de gestiones en beneficio de la comunidad, ya sea para el arreglo de caminos, la iglesia o por medio del Comité de Padres de familia, solucionar o gestionar a favor del mejoramiento de las escuelas o de la gestión de programas; por su parte el subdelegado es quien se encarga del cobro de los posibles documentos que la población requiera; por ejemplo constancias domiciliares, cuenta, comunal o certificados que avalen la venta de animales; el dinero es resguardado por un tesorero y anotado por un secretario.

Por su parte, el Comité de Padres de familia (uno por cada escuela) está compuesto por un presidente, un secretario y un tesorero, y se encargan de organizar actividades extraescolares de los niños, festivales, compra de materiales e infraestructura de la escuela y las diferentes actividades que surjan durante el ciclo escolar. Otro comité necesario para la organización de la comunidad es el Comité de Agua Potable, encargado de la administración de Proyectos como la elaboración de un pozo que suministre de agua a la comunidad en colaboración de los emigrantes y recursos del gobierno federal.

La asignación de un rol que adquieren estos sujetos, al tener un cargo en especial, aquellos de mayor peso político, como el delegado y comisariados, propicia las condiciones necesarias y ejercicio del poder para un beneficio propio dentro de la comunidad, decir que una autoridad de la comunidad trabaja para el bien común, sí, pero también y al parecer cada vez más, trabaja para un fin propio ya sea económico o político, que responde a su vez a un objetivo político, de líder y de partido político.
El cuidado y manutención de la iglesia es también un importante elemento para San Pedro y de esto se encarga La Unidad Comunitaria de San Pedro, la que es una asociación civil que se encarga de los trámites para la restauración de la iglesia, esta trabaja con fondos del gobierno estatal y de la comunidad y en conjunto con elementos del Instituto Nacional de Antropología e Historia (INAH), pues la iglesia es considerada como un edificio histórico, por lo que cualquier cambio en su forma o arreglo tiene que estar avalado por esta institución.

La fiesta de San Pedro y San Pablo resume esta expresión: A nosotros nos gusta hacer la fiesta en grande, además es la mejor de todas. El sistema de cargos en San Pedro lo conforman en total sesenta y cinco familias, organizados por dos mayores y tres fiscales constituyendo doscientas personas de la comunidad que asumen el cargo durante dos años, este número es siempre el mismo en el caso de los cargueros del veintinueve como se les nombra, pues la fiesta de San Pedro y San Pablo es celebrada en dos días, el 28 y 29, donde las familias participan un día y el resto el otro. Sin embargo, existen otros cuatro grupos más que se encargan de organizar las siguientes celebraciones importantes para San Pedro: Semana Santa, Todos Santos, doce de diciembre, veinticuatro de diciembre y Noche Buena.

Estas fiestas también cuentan con un grupo de cargueros encargados y tanto la cooperación económica como el número de cargueros es menor, sin embargo, se puede asegurar la participación de toda la población, pues es además un sistema que tiene implícitos derechos y obligaciones, donde el hecho de no cumplir hace que se pierdan derechos. Las represalias son de dos formas: una de tipo social, es decir, la gente no aprueba tal comportamiento y se deja de reconocer en cierta manera su posición dentro de la comunidad, por ejemplo, si una persona que se sabe rechazó el cargo y está en una asamblea y quiere opinar, esta opinión no es considerada. Otra de las represalias tiene que ver con creencias religiosas, donde fuerzas que van más allá en manos de "San Pedrito", se encargan de dar el escarmiento por no haber aceptado el cargo, pues: a las personas que no han aceptado el cargo les pasan accidentes y cosas malas (informante de la comunidad).

Estos cargos no cuentan con alguna paga, al contrario, requieren, además de tiempo, aportaciones económicas para cubrir los gastos de la fiesta. Cada actividad dentro de la fiesta tiene una participación 
específica de los cargueros (hombres y mujeres), niños, y algunos jóvenes; por ejemplo algunos dan el pan y el café en la noche del 28 de junio, otros dan la comida del día 29 , por otro lado, cinco personas se encargan de los fuegos artificiales, etc., los gastos para los grupos musicales son cubiertos con la cooperación de toda la población católica. Sin embargo, la organización dependerá de los mayores y los acuerdos que se tengan con el resto de cargueros, que se cambian cada dos años.

Los jóvenes y niños participan en una danza llamada "los arcos", estos después de asistir a clases, acuden a la iglesia donde después de los rosarios diarios se juntan para ensayar la "danza de los arcos", de la que se encarga un "xihita" (personas que se encarga de poner los pasos para la danza) y los mayores.

Se trata de mostrar la grandeza de la fiesta, y de tener el reconocimiento de lo mismo por parte de todos los presentes, por eso se invita a: niños, compórtense bien no somos bueyes, sino cristianos y la casa de Dios se respeta, ustedes son los futuros cargueros y deben aprender a respetar y comportarse en la casa de Dios.

Las mujeres, por su parte, participan en la elaboración de la comida, tanto para los niños después de sus ensayos como para los invitados que acuden esos días a la celebración, estos invitados son algunas comunidades que se encuentran en los alrededores junto con la imagen de su santo patrón.

Las actividades de los festejos del 28 y 29 (días de San Pedro y San Pablo) empiezan desde temprano, con la "danza de los arcos", acompañados con la música que surge de un violín y un tambor que son tocados por los músicos de la comunidad, para salir a recibir a las comunidades invitadas al pie de la carretera panamericana; una vez que fueron bienvenidas, comienza un recorrido por toda la comunidad en peregrinación cantando y haciendo alabanzas a todos los santos invitados, intercalando con la música de cada comunidad.

Este recorrido termina en la iglesia, en la que antes de entrar al templo se gira alrededor de ella cuatro veces, después, frente a la cruz atrial se persignan cada uno de los representantes de la comunidad, para después entrar al templo y dejar a los santos en el atrio de la iglesia adornado con flores y ahumado con incienso.

$\mathrm{Al}$ amanecer, el día 29 las actividades comienzan con las mañanitas a San Pedro y San Pablo y al término de estas se vuelve a hacer una misa en compañía de todas las comunidades, recordando la invitación para la próxima fiesta, al mismo tiempo que las comunidades invitadas hacen explícitas las diversas invitaciones a sus propias celebraciones, todo enmarcado en una cuestión de reciprocidad.

En este caso, los cambios referentes a la presencia de estos grupos protestantes están trastrocando una parte importante de la comunidad, pues es la fiesta de San Pedro y la cooperación en ella, lo que de alguna manera sostiene aún fuertes elementos significativos. Aspectos importantes son, que ante la importancia de esta fiesta en particular, las personas que se adscriben en doctrinas protestantes como testigos de Jehová o evangelistas únicamente cooperan para el grupo musical, y responden a su obligación de tener dentro de su casa a San Pedro, pues es esa la obligación que se tiene que cumplir al formar parte de la comunidad y vivir en ella. La presencia de estos grupos está provocando conflictos entre la población católica y protestante, referentes a la participación y roles que se deben asumir en ellas.

Nosotros no tenemos que cooperar en esas fiestas porque no creemos en eso, aunque vivamos aquí, por otro lado, la población católica argumenta, viven aquí y no quieren cooperar pero sí viven aquí y sí gozan del prestigio que tiene la fiesta y si no cooperan en este mundo sí en el mundo de los muertos, de lo contrario si no cooperan no tendrán acceso al panteón. Provocan; que se divida la comunidad mucho más que los partidos políticos pues con ellos no se puede hablar ni llegar a acuerdos y se escudan en ese de la libertad de creencias.

Como menciona la gente, la importancia de la fiesta radica en la cantidad de trabajo y organización que se tiene que hacer, por ello los cargos más importantes son los que se ocupan de la fiesta, los cargos civiles no, esos no trabajan solo se dedican a cargar un fólder y ya.

\section{Pueblo Nuevo: mayordomos al por mayor ${ }^{7}$}

La comunidad tiene dos iglesias, en 1973 quedó dividida en dos barrios. En el barrio primero quedó la de la Virgen de la Inmaculada Concepción, patrona de la comunidad, cuya fiesta se celebra el 8 de diciembre, en el barrio segundo quedó una iglesia de menor tamaño que festeja a la Virgen de San Andrés el 15 de diciembre. Además de las iglesias hay un espacio llamado el llanito, donde hay una Santa Cruz a la que acaban de construirle una capilla. 
En total en la comunidad existen 96 mayordomos, 24 de estos pertenecen exclusivamente al barrio segundo en una sola festividad: la del 15 de diciembre. Los 72 restantes se encuentran repartidos en partes iguales entre los dos barrios y todas las demás fechas del calendario ritual se llevan a cabo en el barrio primero, con dos mayores por festividad, uno de cada barrio.

Cada cuadrilla de mayordomos está formada por un mayordomo principal de cada barrio y el número restante de auxiliares del mayor, además de danzantes, músicos y rezanderos; en el caso de los rezanderos, cada iglesia resuelve el número de estos por ciclo, que abarca del jueves de Corpus al 25 de diciembre A lo largo del año se distribuyen de la siguiente manera, a estas se añaden tres festividades más que se han incorporado al ciclo aunque no cuenten con mayordomos exclusivos: 10 de mayo: Día de las Madres. 20 de mayo, procesión a Acambay para bendecir cirios. 1 de diciembre al 9 de diciembre, llegada del Padre Jesús. Desde hace 5 años hay además una Virgen de Guadalupe peregrina, que se instala en las casas que quieran recibirla y pagar la misa y se queda en la localidad dependiendo del número de casas que la reciban.

El fiscal es el encargado del cuidado de la iglesia, ayuda al sacerdote en las misas, toca las campanas antes de la celebración los domingos, recauda fondos junto con los cargueros para las necesidades de la iglesia. Cada carguero da una cantidad determinada, y la comunidad una cantidad voluntaria, para la reconstrucción de la iglesia, los mismos cargueros ponen la mano de obra, el dinero es solo para material.

Cada carguero tiene la responsabilidad de la fiesta, los cargueros tienen que costear monetariamente la festividad, adornar la iglesia; comprar juegos pirotécnicos, pagar la misa, buscar a sus danzantes, conseguir sus vestimentas, dar la comida y la bebida para la comunidad. Cada 20 de mayo van en procesión a Acambay con sus cirios, el 21 de mayo se pide misa y se bendicen los cirios, se amarran en manojos, los guardan y en cada víspera de la fiesta sacan sus cirios los prenden y los colocan en la iglesia.

Durante el año los cargueros deben acudir a la iglesia cada sábado para florearla y limpiarla, para hacer el llamado a los cargueros, el fiscal conecta una consola y pone música, ya sean las mañanitas o cantos a la Virgen, a las 5 de la mañana, cuando están todos los cargueros. Los rezanderos comienzan a cantar el rosario, colocan un petate a lo largo de la iglesia, donde comienzan a bajar los floreros del altar, donde las mujeres se encargan de adornar los jarros. Al final levantan el petate y lavan el piso del atrio mientras los hombres hacen la limpieza del altar mientras se termina de cantar el rosario.

El fiscal que es el encargado de dar el aviso a las personas que les toca tomar el cargo, tiene una lista de toda la comunidad, en esta lista se encuentran registrados los jefes de familia, en caso de que no esté el hombre, la mujer, esposa o viuda se le da el cargo, a los jóvenes que dejan los estudios y cumplen la mayoría de edad, y aquellas personas, que no viven necesariamente en Pueblo Nuevo, pero que de alguna manera obtienen una cantidad monetaria, ya sea en algún trabajo o negocio.

Para el cambio de cargo, el fiscal tiene la obligación de ir a buscar a la persona a su casa, avisarle que le toca el cargo durante el año, si esta persona no acepta, el fiscal regresa junto con todos los cargueros, si no acepta el fiscal, los cargueros y el delegado, insisten que tiene que tomar el cargo, si aún no acepta, el fiscal, los cargueros, y el delegado, lo llevan a Acambay, para que obligatoriamente se haga responsable del cargo que le corresponde para los miembros de la comunidad, es obligatorio aceptar un cargo.

Cada cargo dura un año, rotando en el mes de diciembre, donde el carguero entrega su cargo con un manojo de trigo, un paliacate y un copal. Además de los mayordomos, la comunidad también participa en las actividades de la iglesia, una de ellas es tocar la campana en las tres albas del día. 02:00 horas, 12:00 horas y 20:00 horas. El fiscal entrega las llaves de la iglesia a una familia encargada de ir a tocar la campana a la iglesia. Al final de la semana el jefe de familia entrega la llave a la familia vecina, y así recorre la llave toda la comunidad.

\section{San Francisco Shaxni: entre delegados y padrinos ${ }^{8}$}

San Francisco Shaxni es la segunda comunidad indígena más grande del municipio, solo detrás de Pueblo Nuevo. El pueblo está dividido por ocho barrios y su centro se caracteriza por ser una zona media, donde no es fácil distinguir entre gente mestiza y gente otomí; ahí es donde se concentran todas las actividades principales y se encuentran los servicios educativos, religiosos y de abasto, económico o de consumo. Los negocios pertenecen por lo general a 
gente mestiza, como son las carnicerías, las tiendas, las papelerías, ferreterías-casa de materiales, los centros de salud, etcétera. Es por eso que se observa que los dueños son de corte mestizo, pero es posible señalar que en esta zona centro también hay gente otomí que se ha involucrado de diferentes maneras con la población mestiza.

Los espacios de lo público en San Francisco se pueden ver en la organización y en las acciones colectivas de la comunidad que se ejercen por medio de una asamblea y que tienen como propósito lograr la representatividad que exige el municipio. Se trata de un entramado de cargos civiles y religiosos llevados a cabo por comités que se asignan según lo que determina la votación. Esto implica esperar a que el municipio convoque a una asamblea y proponer candidatos que se perfilan en las pláticas por los caminos a las tiendas, en las reuniones de trabajo, en las fiestas y en todos los lugares donde se cuestiona su actuar, su grado de compromiso y su transparencia. Las principales autoridades civiles de la comunidad son el presidente de los bienes comunales y el delegado ante el municipio, este tiene varias funciones y no recibe sueldo alguno, dura por un periodo de tres años, aunque el actual delegado de la comunidad es el mismo sujeto que trabajaba para el ayuntamiento desde hace siete años, lo que le permitió quedar exento del trabajo para que se dedicara a cumplir sus funciones en la comunidad.

El delegado tiene la responsabilidad de organizar eventos civiles y religiosos, durante estos organiza el comercio ambulante, la feria y distintas actividades culturales. Asimismo se encarga de la gestión de apoyos ante el municipio como son el reparto de despensas, asignación y distribución de diferentes programas para asfaltar caminos, construcción de drenajes, convocar a faenas en los diferentes barrios, etcétera. Otra de sus ocupaciones es la de hacer algún trabajo o servicio a la comunidad: estructura o convoca a asambleas para formar comités (como el comité para el agua potable, la compra o el arreglo de bombas para el sistema de rebombeo) y distribuye los apoyos para la gente de la comunidad.

El delegado también tiene la responsabilidad de impartir justicia y reconciliar problemas que pueden ser resueltos de manera inmediata sin la necesidad de acudir a instancias judiciales del municipio, por ejemplo, en el caso de peleas entre cónyuges o pequeñas riñas entre personas o diferentes barrios. El rol como delegado consiste en gestionar los recursos para las distintas obras, realizar constancias a la gente de la comunidad. En palabras de un informante: "no nos pagan solo por el orgullo de haber servido al pueblo" (don Camilo).

Por todo esto, el delegado es la figura más representativa en la comunidad y ante el municipio, este papel que desempeña lo convierte en el lazo político más importante, mediante este la comunidad tiene un diálogo directo con el presidente municipal y con los distintos líderes. De esta forma se convierte en el responsable a convocar, informar y resolver los problemas, gestar acuerdos dentro de la comunidad. Algunos informantes anónimos nos comentaron lo siguiente, respecto de la figura del delegado:

Hace algunos años, elegimos a un delegado por ser otomí, pensamos que eso nos daría más prioridad ante el municipio y las otras instituciones, pero resultó contraproducente, no pudo ni gestionar el cemento para terminar su propio camino y los programas de construcción de casas los dieron a sus conocidos, no fue parejo (Comentario anónimo).

Aquí todo el que es del pueblo tiene el derecho y la obligación de participar de distinta manera asumiendo un cargo. Tratamos de ser parejos y de ser partícipes en distribuir los cargos, pero a los otomíes les interesan más los de la iglesia (Comentario anónimo).

Como delegado no solo tiene funciones administrativas, sino también compromisos y lealtades ante quienes lo respaldan. Con el fin de ejecutar distintas acciones colectivas también es quien tiene a su cargo la distribución de apoyos del municipio que son los detonadores que propician la organización, las acciones y las luchas por el recurso al interior de la comunidad, favoreciendo reuniones informales y pláticas en las que se discute acerca de la posible repartición y se cuestiona la representatividad.

Por otro lado en San Francisco Shaxni -una comunidad otomí-mestiza- en relación al proceso político, tenemos la participación en asuntos del gobierno municipal, en donde la emisión del voto y la presencia de los partidos es la parte visible del proceso actual, y por otro lado tenemos la parte no visible, que son dos elementos que han permitido el control y la continuidad del partido que tiene el gobierno. 
Ampliando la explicación de la parte no visible del proceso político de San Francisco Shaxni, encontramos que uno de los elementos son las situaciones de participación en donde se entrelazan los espacios seculares y los espacios religiosos en la vida social, existiendo gente con cargos seculares como diputados y presidentes municipales, que participan y gestionan cooperación. Esta parte del proceso es una contradicción dentro de una estructura que mantiene separadas la vida política y la vida religiosa. Veamos la siguiente narración:

Se nombró un primer comité pro-construcción, confiándole 'la oportunidad de servir independientemente de las simpatías y militancia política de sus miembros por el PRD'. Una vez en funciones, al presentarse irregularidades en las cuentas y algunos desvíos, se tuvo que remover el comité, ya que la gente cuestionaba el uso indebido de recursos, se rumoraba, se decía que compraban el tabique más barato y lo reportaban con un precio más alto, de ahí que se tuviera que remover el comité y votar por uno nuevo que agilizara la construcción, ya que el anterior comité todos eran miembros del PRD, además de no inspirar confianza y transparencia en el uso de recursos, los diputados y el mismo presidente municipal que son del PRI no les daban apoyo, el nuevo comité quedó conformado por el presidente municipal de Acambay que es de San Francisco, él se vería obligado poder dar mayor apoyo (Comentario anónimo).

Otro de los elementos visibles es que en el municipio de Acambay se creó la figura de un padrino para cada comunidad que es un funcionario del municipio, que plantea las necesidades y convoca a la organización, reconociéndole como quien impulsa proyectos y se preocupa por la necesidades del pueblo. Esta parte no visible es la situación de injerencia y control, ya que se evidencia una de las etapas del proceso político.

A San Francisco le tocó la directora de desarrollo social, quien muchos reconocen como la impulsora de la organización de las mujeres y de la construcción del salón, quien les planteó la necesidad de crear un comité: "En una plática nos comentaban que: 'El salón facilitará la reunión de las mujeres para hacer distintos proyectos: talleres de costura, de alimentación, hacer fiestas, somos
380 mujeres de todos los barrios"" (comentario de la señora Ana).

La construcción del nuevo salón del pueblo facilita a las mujeres organizar proyectos productivos y gracias a ello se distribuyen mejor en las formas de trabajo; también se crea una fuente de empleo dentro de su propio lugar de origen sin tener la necesidad de salir a otro lugar y, así será posible cubrir la necesidad de ingresos vía trabajo, con la muestra de que se emplean en formatos modernos de maquila, bajo una organización y cooperación comunitaria.

Por esta razón, la comunidad se vio obligada a construir un espacio más grande que tuviera funcionalidades múltiples como el salón del pueblo que se ocupó por la maquiladora; la gente del pueblo nos comentó y señaló esa obra en curso, en un primer momento estaba en proceso de edificación que exhibía paredes inconclusas y aún no tenía techo ni piso. Pero la gente nos explicó que pronto se había convertido en un salón destinado a las mujeres de la comunidad, que fue una obra promovida por un padrino del municipio a la comunidad.

Basados en los postulados del típico sistema de cargos hemos confeccionado el siguiente esquema, experimentando con la información etnográfica de las cuatro comunidades aquí tratadas.

Donde las etnografías aquí presentadas contiene información concreta al respecto, se indica la página del manuscrito en la que se encuentra dicha información, si no hay indicación de alguna página significa que se desprende del contexto.

Una " $X$ " significa que no se encuentra información al respecto en la etnografía y se tiene que buscar en una posterior investigación o en comunicación con el autor de la etnografía.

La información en el renglón 8, si todos los miembros de la comunidad participan solo o un porcentaje de la participación, depende de un cálculo del número de miembros de la comunidad, el número de cargos en el sistema, la duración de los cargos, y la relación entre esos factores, teniendo en mente los cálculos de la participación en las comunidades de Zinacantán y Amatenango del Valle en Chiapas (Cancian, Nash).

La primera vez que Leif Korsbaek intentó calcular la participación en el sistema de cargos en mi investigación en San Francisco Oxtotilpan (Korsbaek, 2009), resultó que la participación en San Francisco Oxtotilpan era del 140\%, por la sencilla razón de que una buena parte de la población de la comunidad vive fuera de esta, pero participan activamente en el sistema, ocupando los cargos cuando 


\begin{tabular}{|c|c|c|c|c|}
\hline & Pathé & $\begin{array}{l}\text { San Pedro de los } \\
\text { Molcajetes }\end{array}$ & Pueblo Nuevo & $\begin{array}{c}\text { San Francisco } \\
\text { Shaxní }\end{array}$ \\
\hline 1. Número de oficios & $\mathrm{X}$ & 65, p. 17 & 96, p. 20 & $\mathrm{X}$ \\
\hline 2. Entre los miembros & Sí & Sí & Sí & Sí \\
\hline 3. Un período corto de tiempo & Un año, p. 15 & Dos años, p. 17 & Un año, p. 21 & Un año, p. 21 \\
\hline 4. Ordenados jerárquicamente & Sí, p. 14 & Sí, p. 16 & Sí & Sí, p. 22 \\
\hline 5. No reciben pago alguno & Sí, p. 14 & Sí, p. 17 & Sí, p. 20 & Sí, p. 22 \\
\hline 6. El cargo significa un costo considerable & Sí, p. 15 & Sí, p. 17 & Sí & $\mathrm{X}$ \\
\hline 7. El cargo confiere prestigio & Sí, p. 14 & Sí, p. 17 & Sí & Sí \\
\hline $\begin{array}{l}\text { 8. Todos los miembros de la comunidad } \\
\text { participan }\end{array}$ & Sí & Sí, p. 17 & Sí & Sí \\
\hline 9. Existe una jerarquía religiosa & Sí, p. 13 & Sí, p. 18 & Sí, p. 19 & Sí, p. 22 \\
\hline 10. Existe una jerarquía política & Sí, p. 13 & Sí, p. 16 & Sí, p. 20 & Sí, p. 22 \\
\hline $\begin{array}{l}\text { 11. Las dos jerarquías están íntimamente } \\
\text { relacionadas }\end{array}$ & Sí, p. 13 & Sí, p. 19 & Sí, p. 21 & Sí, p. 22 \\
\hline $\begin{array}{l}\text { 12. Un miembro de la comunidad es conside- } \\
\text { rado como pasado o principal }\end{array}$ & $X$ & $\mathrm{X}$ & $\mathrm{X}$ & $X$ \\
\hline
\end{tabular}

sean nombrados. El correspondiente cálculo para las comunidades de Acambay depende de un estudio de la migración en el municipio que estamos al punto de iniciar. Ya en este momento tenemos algunos datos iniciales: que la migración es altísima, que una buena parte de los migrantes (aprox. el 80\%) no tienen nada de ganas de regresar a México.

Finalmente, un comentario. Ha sido comprobado ampliamente que el típico sistema de cargos no es típico en el estado de México (Korsbaek, 2000, 2002, 2007), por lo menos en tres o cuatro puntos difiere del modelo del Sureste. La evidente consecuencia es que la respuesta etnográfica en Acambay de los renglones 4 (el ordenamiento jerárquico de los cargos), 6 (si significa un costo considerable, a nivel individual del carguero o de una red de compadres y comadres), 8 (si todos participan), un dato que tiene que ver con la proliferación de sectas religiosas o iglesias no católicas, donde viene al caso la existencia de la iglesia "La Luz del Mundo" (Vargas, 2013) en el municipio de Acambay.

Ya que el punto de partida de la presente investigación ha sido la idea del típico sistema de cargos, los resultados finales de la investigación serán un argumento muy fuerte en la discusión acerca de las características del sistema de cargos en el estado de México.

\section{Conclusiones}

Como mencionamos, en el estado de México y particularmente en el municipio de Acambay hemos observado que el "típico sistema de cargos" no es típico en las comunidades indígenas del municipio de Acambay, siendo las principales diferencias: en primer lugar la participación, esta no es clara, pues se articula lo político y lo religioso; asimismo, la responsabilidad de los gastos relacionados con la ocupación de un cargo provienen tanto de la comunidad como de la parte secular.

Por ello pensamos que la particularidad de los cargos tiene que ser pensada en términos de la secularidad como un elemento que somete al individuo al interés de la colectividad. Los cargos civiles y religiosos son el espacio donde la fe de la comunidad se seculariza y queda sustituida por el interés de la colectividad, es decir, están insertos en un mundo moderno que se caracteriza porque ha establecido procesos de cambio en las prácticas colectivas que tienen a la religión como vínculo de reconocimiento, pero al mismo tiempo de organización de la vida política y social.

Talal Asad escribe que el problema de lo secular se ha convertido en un tema de discusión, ya que hace posible reconocer las tradiciones religiosas e instituciones de la comunidad, como son el sistema de cargos, permiten que se instituya una cultura secularizada en el mundo religioso, ya que "sería muy simplista definirla simplemente como la separación de las religiones de las instituciones seculares de los gobiernos, en cuanto no se trata solo de eso" (Asad, 2003:1); por ello tratamos de mostrar que en los grupos indígenas de Acambay no es fácil dar por establecida la separación, ya que la modernidad se expresa en sus propios términos.

La secularización solo es la mitad de la vida en el mundo moderno, ya que la organización y dinámica de lo social está alrededor de lo sagrado 
(fiestas, construcción de iglesias, intercambio de santos, motivos para socializar y otros), por tanto la vida se puede ver como dual, con dos caras de la vida moderna en las comunidades campesinaindígenas, otomí: "La modernidad no implica primariamente un reconocimiento de la realidad, sino una manera de vivir en el mundo. Como es esto válido en cualquier época, lo distintivo de la modernidad como época histórica la incluye como un proyecto político y económico" (Asad, 2003:16), de ahí que la modernidad se expresa de distinta forma, aun cuando la religión sea el vehículo de la organización.

Pensamos que lo secular no es una separación de lo religioso, ni una simple ruptura con ello (es decir, no es la oposición a lo sagrado, ni algo que lo excluye). Consideramos que lo secular es un concepto que abarca comportamientos, conocimientos y que estos caracterizan a la sociedad moderna, que al presentarse en las comunidades campesinas e indígenas, las prácticas y la vida social trasciende, ya que van de la mano tanto de espacios seculares como religiosos. Es más que una dicotomía (modernidad y tradición) que se engloba en discursos racionales, en acuerdos públicos.

En los términos de la modernidad ese rasgo que es la secularización liberal, combina de manera curiosa la ingenuidad con el cinismo, ya que sé que si bien se pretende prescindir de Dios y de la religión, se pone a prueba ante una tendencia a la secularización de lo religioso en su injerencia política, que se muestra en las distintas narrativas y en los aconteceres en espacios de la vida pública.

En este sentido ese imaginario y ordenamiento institucional de tener las dos esferas separadas (la religiosa y la política) se ponen a prueba apelando a comunidades pequeñas o indígenas, donde ese ordenamiento e imaginario más que una división es un punto de intersección que define los destinos de la vida política de gente que es partícipe de ambas esferas, como son los cargos.

Es posible señalar que la secularización realmente existente se presenta en términos administrativos donde la presencia de lo eclesiástico en la política se presenta en situaciones de coexistencia. Teniendo ese rasgo de la vida moderna en las comunidades indígenas y campesinas (la secularización) como el ordenador de las instituciones terrenales y políticas se contrapone relativamente al mundo de la creencia divina y celestial.
Finalmente intentamos mostrar etnográficamente la secularidad como elemento esencial de la modernidad que pasa por someter al individuo al interés de la colectividad donde la fe de la comunidad, es la creencia en común, siendo la religiosidad plasmada en un sistema de cargos, que es al mismo tiempo un interés común, y que para un sujeto integrante de una comunidad, sus simpatías políticas son una plataforma que le permite expresar sus creencias asumiendo un cargo religioso.

Ahora bien, otra ingenuidad es dar por establecido que en la vida social se da por completo la eliminación de lo sagrado, ya que en el transcurrir cotidiano de comunidades pequeñas constantemente se apela a lo divino, que en los términos weberianos estamos ante el re-encantamiento de las imágenes del mundo que se presentan en espacios religiosos (fiestas, construcción de iglesias, motivos para socializar y otras instituciones); siendo la secularización solo una parte de la vida en el mundo moderno y los religioso una tendencia a la secularización.

Es necesario afirmar que las formas actuales del Estado moderno que se caracteriza como secular transmite la idea de que es un papá como Dios y padre de familia donde todos obedecen, ya que él se ha sacrificado por sus hijos: "Basta subrayar que según Hobbes el Estado surge de un pacto nacido del miedo, donde se considera la paz como un bien supremo que merecía cualquier sacrificio, el Estado instauró un pacto válido aun cuando haya surgido bajo la presión y el miedo" (Ginzburg, 2014: 34,35). Entonces la única figura de respeto y reverencias es la de Dios, ante esta confusión de autoridad, poder y legitimación, se ha facultado al Estado para el ejercicio de su función, donde este impone el miedo y el castigo, y el castigo en este caso para una comunidad es quedarse sin recursos de las instituciones del Estado y de los proyectos gubernamentales.

Finalmente, el sistema de cargos es conocido como una institución comunitaria, que se expresa ahí, en la comunidad, y que nos permite observar las características particulares desde el planteamiento etnográfico de la idea del típico sistema de cargos, que como una institución en estas comunidades otomíes, adquiere características propias, cuando los sujetos se relacionan con el municipio. Consideramos conveniente recalcar que el sistema de cargos en Acambay no se limita solo a aspectos de la jerarquía religiosa, sino que se presentan en este de forma 
mezclada, patrones de interés y sobrevivencia política que no se desprende culto religioso.

Mencionamos anteriormente que "el texto se puede considerar como una segunda parte de un artículo acerca de "la política en San Francisco Oxtotilpan" (Korsbaek, 2011)", y faltaría señalar que los datos etnográficos provienen de trabajos de campo muy diverso, hecho originalmente sin atención a la dimensión comparativa en el marco del municipio.
También este texto ha tenido como finalidad poner a prueba el agotamiento del paradigma del sistema de cargos, que hoy no es la moda en las preocupaciones de la antropología social, por ello en este momento tenemos un programa de continuar con el trabajo de campo, en una dimensión formativa y de investigación, de estudiantes que tienen como punto de partida las existentes etnografías con la tarea de actualizar, sistematizar los datos, que al equipo nos permita continuar con este programa de investigación.

\section{Referencias Citadas}

Álvarez Fabela, Reyes L. \& Juana Monterrosas Flores 2007 "Un mayordomo no hace sistema: Los cargos en San Juan Atzingo", Ponencia presentada en Querétaro, 2007.

Asad, Talal

2003 Formations of the secular. Christianity, Islam, modernity. Stanford University Press.

Cancian, Frank

1976 Economía y prestigio en una comunidad maya, Instituto Nacional Indigenista.

Carrasco, Pedro

1979 "La jerarquía cívico-religiosa en las comunidades de Mesoamérica: antecedentes precolombinos y desarrollo colonial", en J.R. Llobera, comp.: "Antropología Política", Anagrama, Barcelona, 1979: 323-340.

Chevalier, François

1944 "Los municipios indígenas en la Nueva España, 15201620", "Les municipalités indiennes en Nouvelle Espagne", Anuario de Historia del Derecho Español, Vol. XV, 1944: 352-386. Traducción de Leif Korsbaek.

Dumont, Louis

1970 Homo hierarquicus, London, Paladin Books.

Fortes, Meyer

1962 "Ritual and Office in Tribal Society", en Max Gluckman, Ed.: The Ritual of Social Relations, Manchester, Manchester University Press, 1962: 53-88.

Ginzburg, Carlo

2014 Miedo, reverencia, terror. Cinco ensayos de iconografía política. Libros de Contrahistorias. México.

Korsbaek, Leif

2000 "El sistema de cargos en las comunidades indígenas en el estado de México", en la revista Expresión Antropológica del Instituto Mexiquense de Cultura, Número 10: 30-47.

Korsbaek, Leif

2002 "Comunidades indígenas y sistemas de cargos en el estado de México", en la revista México Indígena, Nueva Época, Vol. 1, № 3, diciembre de 2002: 35-42.

Korsbaek, Leif

2007 "El sistema de cargos en el estado de México", en la revista Textual, $\mathrm{N}^{\circ}$ 50: 67-97.

Korsbaek, Leif

2009A La etnografía de una comunidad matlatzinca en el estado de México: el sistema de cargos y la neoetnicidad en San Francisco Oxtotilpan, municipio de Temascaltepec, Tesis Doctoral en Ciencias Antropológicas, Universidad Autónoma Metropolitana Iztapalapa.
Korsbaek, Leif

2009B "Los peligros de la comunidad indígena y sus defensas", en la revista Ra Ximhai, Vol. 5, No 3 (septiembre-diciembre 2009): 373-385.

Korsbaek, Leif

2011 "La política en San Francisco Oxtotilpan", en Revista Mexicana de Ciencias Políticas, № 211: 103-120.

Korsbaek, Leif

2012 "El cambio de las instituciones comunitarias bajo el impacto del neoliberalismo", Ponencia presentada en el 53. Congreso Internacional de los Americanistas, Viena, julio 2012.

Korsbaek, Leif

2014 "Dossier. Las instituciones de defensa de la comunidad", Revista La Pacarina del Sur, $\mathrm{N}^{\circ} 20$.

Korsbaek, Leif, comp. 1996 Introducción al sistema de cargos, Toluca, Universidad Autónoma del Estado de México.

Kroeber, Alfred L.

1948 Anthropology, New York, Harcourt, Brace.

Leach, Edmund R.

1965 "Political Systems of Highland Burma", Boston, Beacon Press (org. 1954).

Leach, Edmund R.

1967 "Introducción”, en Leach \& otros: "Estructuralismo, mito y totemismo", Buenos Aires, 1972: 7-22.

Lévi-Strauss, Claude

1953 "La noción de estructura en etnología”, en Claude Lévi-Strauss: Antropología estructural, Barcelona, Paidós, 1987: 29-337.

Linton, Ralph

1956 Estudio del hombre, México, FCE.

Lira, Andrés

1987 "Idea y realidad en la formación constitucional del municipio", en B. Boehm de Lameiras, coord.: El municipio en México, Zamora, El Colegio de Michoacán, 1987: 51-66.

Medina, Andrés

1983 "Los grupos étnicos y los sistemas tradicionales de poder en México”, en la revista Nueva Antropología, Vol. V, $N^{\circ}$ 20: 5-30.

Medina Hernández, Andrés

1987 "Los que tienen el don de ver: los sistemas de cargos y los hombres de conocimientos en los Altos de Chiapas", en Barbro Dahlgren, ed.: "Historia de la religión en Mesoamérica y áreas afines", UNAM, México, 1987: 153-176. 
Millán, Saúl

2003 El cuerpo de la nube. Etnografía de las representaciones huaves sobre las jerarquías civiles y religiosas, Tesis doctoral de la Universidad Autónoma Metropolitana Iztapalapa, México.

Nadel, S. F.

1935 "State and Community among the Nupe", Africa, Vol. 8: 257-303.

Parsons, Talcott

1986 Biografía intelectual. Universidad Autónoma de Puebla, Puebla.

Parsons, Talcott

1982 El sistema social. Alianza Editorial. Madrid.

Pozas Arciniega, Ricardo

1977 Chamula, México, Instituto Nacional Indigenista.

Radcliffe-Brown, Arthur R.

1940 "On Social Structure", en A. R. Radcliffe-Brown:

"Structure and Function in Primitive Society", London, Cohen \& West, 1952: 188-204.

Reina, Leticia

2015 Cultura política y formas de representación indígena en México, siglo XIX. Instituto Nacional de Antropología e Historia. 106-107.

Rossi, Ino \& Edward O'Higgins

1981 Teorías de la cultura y métodos antropológicos, Barcelona, Anagrama.

Simmel, Georg

1910 "How is Society Possible?", en Maurice Nathanson, ed.: Philosophy of the Social Sciences: A Reader, New York, Random House, 1963: 73-92.

Sosa, Isidro

2011 Pathé. Ritualidad patronal de una comunidad del noroeste del Estado de México, Escuela Nacional de Antropología Social, Tesis Doctoral en Antropología Social.
Tax, Sol

1937 "The Municipios of the Midwestern Highlands of Guatemala", American Anthropologist, Vol. 39, 1937: 423-444 (publicado en español en Leif Korsbaek, comp.: "Introducción al sistema de cargos", Facultad de Antropología de la UAEM, Toluca, 1996: 87-112).

Topete Lara, Hilario

2007 P'intekwa: la forma de hacer, vivir, ser en San Juan Nuevo Paranguricatiru, Michoacán, Tesis doctoral, Escuela Nacionald e Antropología e Historia.

Torres, José de Jesús

2000 "El hostigamiento a 'el costumbre' huichol: Los procesos de hibridización social", Zamora, El Colegio de Michoacán/la Universidad de Guadalajara.

Turner, Victor W.

1969 The Ritual Process, Harmondsworth, Penguin Books. Vargas Torices, Carla Guadalupe

2013 "Más que una institución religiosa ... Somos la luz del mundo. Estudio de la diversidad religiosa en Acambay, Estado de México", Tesis de Licenciatura en Antropología Social, Escuela Nacional de Antropología e Historia (ENAH).

Vogt, Evon Z.

1965 "Réplica estructural y réplica conceptual en la cultura zinacanteca", en Evon Z. Vogt, ed.: Los zinacantecos: un pueblo tzotzil de los Altos de Chiapas, Instituto Nacional Indigenista, SEP-INI No. 7, México, 1966: 129-141.

Vogt, Evon Z.

1973 "Gods and Politics in Zinacantan and Chamula", Ethnology, Vol. 12 No. 2: 99-113.

Wilson, Monica

1967 "Nyakyusa Age Villages", en Cohen \& Middleton, eds.: "Comparative Political Systems", New York, Garden City, Natural History Press, 1967: 217-228.
1 Una versión anterior de este texto fue presentada como ponencia en el Tercer Congreso Internacional de Antropología AIBR, Puerta Vallarta, México, noviembre de 2017. El texto se puede considerar como una segunda parte de un artículo acerca de "la política en San Francisco Oxtotilpan" (Korsbaek, 2011).

2 Para una discusión más amplia y más profunda de los rasgos generales del estudio antropológico del sistema de cargos, que Andrés Medina (1987) llama, con cierto sarcasmo, "cargología", se refiere a Korsbaek, comp., 1996, donde se encuentran las pertinentes referencias bibliográficas.

3 La información etnográfica proviene de la tesis doctoral de Isidro Sosa (Sosa, 2011).

4 Reunida la Asamblea, proponen a quien desean como delegado (generalmente nadie se propone para el cargo). La gestión (de delegado, subdelegado, tesorero y presidente de bienes comunales, con sus respectivos suplentes) tiene una duración de tres años. Al término de este, las autoridades municipales convocan a Asamblea General para elegir Nuevo Delegado; a esta Asamblea asiste un representante municipal que da validez a dicho proceso. El Delegado saliente tiene que entregar el sello (que lleva el símbolo de Acambay con la frase: Delegado Municipal).

5 No se quiere decir que todas las personas propuestas y elegidas acepten, pues dentro de la misma Asamblea se les pregunta si están en disponibilidad para llevar a cabo los trabajos que implican el cargo. Si la respuesta es negativa, el proceso reinicia para proponer y elegir a otras personas (comentario de Isidro Sosa).

6 La información etnográfica proviene del informe de prácticas de campo de Jessica Contreras (2005), y ha sido actualizada por breves estancias en San Pedro de los Molcajetes de Martín Ronquillo, Leif Korsbaek y José Antonio García entre 2011 y 2016.

7 La información etnográfica proviene del informe de prácticas de campo de un equipo de alumnos en 2005 (con la participación de Alejandra Bautista, Sofía Castillo, Natasha Montes, Inés Sandoval, Lourdes González, Benito Jiménez, Isabel Escudero).

8 La información etnográfica se debe a estancias en la comunidad de Martín Ronquillo e Israel Lira Sánchez entre 2012 y 2014. 